\title{
CÁNCER CERVICAL: CITOLOGÍA EN BASE LÍQUIDA, CONVENCIONAL Y OTRAS PRUEBAS DE TAMIZAJE
}

Piedad Campo MD*, Luis Jairo Bonilla MD **, Adriana Calderón MD ***

\section{Resumen}

La citología cervicovaginal como herramienta diagnóstica se inició en el siglo XIX con el médico griego George Papanicolaou y se implementó en los programas de tamizaje de cáncer a mediados de 1960, logrando una reducción de la mortalidad $(80 \%)$ a nivel mundial. Como limitación está la baja sensibilidad que oscila entre 30 y $87 \%$, con promedio de $53 \%$. La mortalidad por cáncer cervical mundial es de $86 \%$ y $88 \%$ en países en vía de desarrollo. En Colombia la tasa de mortalidad ajustada por edad es de 18,2 por 100.000. Esto se debe al control de calidad inadecuado y la pobre actualización permanente de los citohistotecnólogos, sumada al alto número de lecturas realizadas en la jornada laboral, llevando a un sobrediagnóstico de atipia de células escamosas de significado indeterminado (ASCUS). Además influyen factores como la no toma de la citología por el bajo nivel socioeconómico y la falta de afiliación al régimen de seguridad social. La citología en base líquida (CBL) resuelve cinco problemas: 1) falta de captura de la totalidad de la muestra, 2) fijación deficiente, 3) distribución aleatoria de células anómalas, 4) existencia de elementos perturbadores y 5) mala calidad del frotis. Esta técnica incrementa la sensibilidad de lesiones intraepiteliales de alto grado y carcinomas, sin variación en la especificidad. Otras pruebas de tamización son la detección y tipificación del virus del papiloma humano (VPH) incluida en el plan obligatorio de salud (POS) 2012, la prueba de reacción en cadena de la polimerasa (PCR), oncogenes RNA E6 Y E7 y la inspección visual con ácido acético y lugol (vía vili) cuya filosofía es "ver y tratar".

Palabras clave: atipia escamosa de significado indeterminado (ASCUS), virus del papiloma humano, citología en base líquida, reacción en cadena de la polimerasa, alto riesgo, neoplasia intraepitelial cervical.

Abreviaturas: ASCUS, atipia escamosa de significado indeterminado, VPH, virus del papiloma humano, CBL citología en base líquida, PCR reacción en cadena de la polimerasa, NIC neoplasia intraepitelial cervical, $A R$ alto riesgo.

\section{CERVICAL CANCER: LIQUID-BASED, CONVENTIONAL CYTOLOGY AND OTHER SCREENING TESTS}

\begin{abstract}
Cervico-vaginal cytology has been used as a diagnostic tool since the early 19th century started by the Greek physician George Papanicolaou and was implemented for cancer screening programs since the mid 1960 s achieving an $80 \%$ reduction in mortality rate worldwide. A low sensibility between 30 and $87 \%$, average $53 \%$, is a drawback. Global mortality rate due to cervical cancer is $86 \%$ and $88 \%$ in developing countries. The age-related mortality rate in Colombia is $\mathbf{1 8 . 2}$ per $\mathbf{1 0 0 . 0 0 0}$ patients. The latter is due to inadequate quality control and lack of update training for
\end{abstract}

Fecha recibido: marzo 26 de 2012. Fecha aceptado: mayo 17 de 2012

* Médica Patóloga, Decana, Facultad de Tecnología en Citohistología. Instructor Asociado, Fundación Universitaria de Ciencias de la Salud. Bogotá DC, Colombia.

** Médico Ginecólogo, Hospital Infantil Universitario de San José. Instructor Asociado, Fundación Universitaria de Ciencias de la Salud. Bogotá DC, Colombia.
*** Residente I de Patología, Fundación Universitaria de Ciencias de la Salud. Bogotá DC, Colombia.

**** Estudiantes colaboradores: Maryuris Cuisman, Luz Andrea Hernández, Tatiana Hurtado, Francy Valenzuela, Olga Negrete. Facultad de Tecnologia en Citohistologìa. Fundación Universitaria de Ciencias de la Salud. Bogotá DC, Colombia. 
cytohispathology technicians, in addition to the high number of readings performed during their work day leading to overdiagnosis of Atypical Squamous Cells of Undetermined Significance (ASCUS). Other factors such as not performing a cervical smear due to low socioeconomic status and lack of affiliation to the social security system are also important. The use of liquid-based cytology (LBC) resolves five problems: 1) failure to capture the complete sample, 2) poor fixation, 3) random distribution of anomalous cells, 4) existence of perturbing elements, and 5) poor quality of the smear. This technique increases the sensibility of high-grade intraepithelial lesions and cancer lesions with no specificity variation. Other screening tests are: human papillomavirus (HPV) detection and typing tests included in the 2012 Health Obligatory Plan (POS) and the polymerase chain reaction tests (PCR), RNA oncogenes E6 and E7 and visual inspection with acetic acid and lugol's iodine (VIA/VILI) in a "see and treat" cervical prevention strategy.

Key words: Atypical Squamous Cells of Undetermined Significance (ASCUS), human papillomavirus, liquid-based cytology, polymerase chain reaction, high risk, cervical intraepithelial neoplasia.

\section{Introducción}

El cáncer cervical causa la muerte a 270.000 mujeres cada año en especial en países en vía de desarrollo siendo prevenible a través del tamizaje en mujeres con lesiones cervicales precursoras asintomáticas y el tratamiento antes de progresar a enfermedad invasiva. En otras palabras "estas muertes son prevenibles". Si una mujer se realiza el tamizaje en la mitad de su vida entre los 30 y 40 años su riesgo de cáncer se reduce entre 25 y $36 \%$.

Desde la introducción de la prueba de Papanicolaou en los años 50 los programas de detección por medio de la citología cervical han tenido éxito mostrando como fortaleza el bajo costo, alta especificad (100\%) y evidencia de microorganismos. Sin embargo, hay limitaciones como la sensibilidad promedio del 53\%, problemas en la toma y muestreo, alto número de extendidos insatisfactorios, problemas de interpretación dados por la incapacidad de identificar células anormales o confusión de los cambios reactivos (metaplásicos vs displásicos) y el alto número de falsos positivos y negativos.

La citología en base líquida es una técnica alternativa en la que se transfiere todo el material celular a un medio fijador a base de etanol o metanol. En nuestro medio disponemos de ThinPred (hologic) y SurePath (TriPath) con lo cual se redujeron los extendidos insatisfactorios y se incrementó la sensibilidad de detección de lesiones intraepiteliales cervicales de bajo y alto grado en 59 a $70 \%$ y se creó la posibilidad de realizar pruebas complementarias como DNA, HPV, captura de híbridos, inmunocitoquímica, inmunohistoquímica y genética molecular.

\section{Objetivo}

Describir el estado actual de la citología en base líquida frente a la convencional, sus características morfológicas, ventajas y desventajas. Ambos estudios son sometidos a la verificación del estándar de oro basado en la colposcopia y la biopsia, con el que se obtienen datos de sensibilidad y especificidad. En esta revisión se comparan las dos técnicas y se muestran nuevas opciones para el tamizaje o cribado del cáncer cervical.

\section{Metodología}

Se tomaron estudios comparativos de las técnicas en base líquida y la convencional, que mostraron nuevas opciones para el tamizaje del cáncer cervical como las pruebas de VPH y la inspección visual con ácido acético. Estos fueron buscados vía web en la base de datos PubMed-MEDLINE y Embase utilizando las palabras claves: liquid-based cytology, conventional cytology, cervical cancer en combinación con monolayer, SurePath, ThinPrep, VPH tests y acetic acid visual inspection. Además algunos estudios los suministraron médicos patólogos investigadores del tema.

\section{Aspectos históricos y estado actual}

La citología cérvicovaginal como herramienta diagnóstica tiene sus inicios a partir del siglo XIX con su 
padre y pionero George Papanicolaou, médico griego que dedicó su vida a estudiar los diferentes tipos, características y géneros de células sexuales y somáticas. Con el tiempo y luego de persistir en investigaciones en el Instituto de Zoología de Münich recibe el grado de doctorado con un trabajo sobre diferenciación y determinación del género del microorganismo Daphnia en 1910.

En 1925 cuando su trabajo estaba en auge logró encontrar anormalidades morfológicas mediante la observación de las células en los extendidos vaginales de mujeres voluntarias y trabajadoras del Hospital de la Mujer en Nueva York, EE.UU. que predicen el diagnóstico del cáncer cervical. En 1928 se habla por primera vez de su técnica de tinción como un método más preciso en la determinación del cáncer en etapas iniciales; en 1940 introdujo este tamizaje por su bajo costo y aplicación masiva. Desde entonces la incidencia del cáncer tipo invasor ha disminuido. ${ }^{1,2}$ La implementación de la citología dentro de los programas de tamizaje de cáncer cérvico uterino ocurrió muchos años después hacia mediados de 1960, logrando una reducción en la mortalidad en un $80 \%$ a nivel mundial. ${ }^{3}$ Por su efectividad demostrada los países desarrollados incluyeron la citología dentro de los programas de cáncer cervicouterino y con ello han logrado disminuir la incidencia de la enfermedad a 7 por 100.000 y la mortalidad a 2.7 por $100.000 .^{4}$

El frotis de Papanicolaou ha mostrado importantes limitaciones y en la actualidad una de ellas, quizás la mas importante, es la baja sensibilidad que oscila a nivel mundial entre 30 y $87 \%$; estudios recientes en centros de referencia de Europa y Estados Unidos han mostrado un promedio de $53 \% .{ }^{5}$ Es el segundo cáncer más frecuente en el mundo con una mortalidad de $86 \%$ y $88 \%$ en países en vía de desarrollo. En América Latina 32.000 mujeres mueren al año, siendo más grave en Nicaragua, Honduras, El Salvador y Bolivia donde la incidencia es de 35 por $100.000 .^{6-8}$

En Colombia se considera la primera causa de incidencia y mortalidad por cáncer en mujeres durante los años 2000 a 2005, como lo mostró la encuesta nacional de demografía y salud (ENDS) que describió la baja cobertura en citología en cuatro departamentos entre 25 y 69 años debida a la ausencia de la toma de muestra durante los últimos tres años. Se encontró una cobertura del $76.6 \%$ que coincide con el resultado a nivel mundial en cuanto al seguimiento y diagnóstico por este método, independiente de muchos otros factores que impiden que sea del $100 \%$ la favorabilidad. Con una tasa ajustada por edad de 36,4 por 100.000 , representa 6.800 casos nuevos anuales y con una tasa de mortalidad ajustada por edad de 18,2 por $100.000 .{ }^{9}$

El segundo gran inconveniente está relacionado con la fase preanalítica que corresponde a la toma de la muestra debido a una carencia de entrenamiento en el personal encargado de su recolección y errores en la instrumentación, preparación del frotis y los relacionados con el paciente.

El tercer inconveniente en la tamización está en la fase analítica que corresponde a la interpretación morfológica de los extendidos clasificados como cambios reactivos benignos (metaplasia escamosa madura e inmadura, presencia de microorganismos) y cambios neoplásicos (lesiones intraepiteliales cervicales de alto y bajo grado y las glandulares endocervicales y endometriales) que conlleva a mala calidad en la lectura de la citología y acceso inoportuno a los servicios de diagnóstico y tratamiento. ${ }^{9}$

Esto se debe al control de calidad inadecuado y la carencia de actualización permanente en lo referente a la morfología por parte de los citohistotecnólogos de los diferentes centros del país, sumado al alto número de lecturas realizadas en la jornada laboral. Al revisar la literatura encontramos los siguientes datos sobre los límites de trabajo en relación al número de láminas leídas en 24 horas recomendadas por las diferentes asociaciones citología y patología ${ }^{10}$ (Tabla 1).

Esto ha llevado a un sobrediagnóstico de atipia de células escamosas de significado indeterminado (ASCUS) que apareció en el sistema Bethesda 2001, tanto en relación con los parámetros citológicos para dicha terminología como para la unificación del enfoque del clínico para el manejo médico acorde con dicho resultado. Hay otros factores que influyen en no realizarse 


\section{Tabla I. Asociaciones de citología y patología}

Sociedad Canadiense de Citología (C.S.C.)

Sociedad Americana de Citología (A.S.C)

Acta de 1988 de mejoras del Laboratorio Clínico

( C.L.I.A. '88)

Sociedad Americana de Citotecnología (A.S.C.T.)

Colegio de Patólogos Americanos (C.A.P.)

Sociedad Británica de Citología (B.S.C.C.)

Límites del Estado de California

Límites del Estado de Nueva York

Centro de cáncer Sloan Kettering, Nueva York

Universidad Médica de Carolina del Sur

Instituto de Citología, Sociedad de Cancer de Baviera-Munich Alemania

Universidad de Nimeja-Netherlands de 60 a 80. máximo 90 preparaciones en 24 horas

máximo 100 en 24 horas. 12.000 casos/año

100 en 24 horas (no menos de 8 horas)

8,400-10,800 casos/año, 80 en 24 horas

9,000 casos/año ( $80 \%$ de rendimiento) 75 en 24 horas

32 casos/ 24 horas. 8 por hora

80 preparaciones en 24 horas

80 preparaciones en 24 horas

60 preparaciones en 24 horas

80 preparaciones en 24 horas

60 preparaciones en 24 horas

40 preparaciones en 24 horas la citología como son bajo nivel socioeconómico, falta de afiliación al régimen de seguridad social en salud, unión conyugal inestable, no haber tenido una consulta de salud en el último año y el bajo nivel educativo, que influyen en la pobre cobertura a nivel nacional con el incremento de la incidencia y mortalidad por esta enfermedad. ${ }^{9}$

Teniendo en cuenta que para la evaluación de muestras satisfactorias el número es de 8.000 a 12.000 células escamosas y de 10 células endocervicales o de la zona de transformación bien conservadas, el frotis de Papanicolaou logra entre 600.000 a 1.2 millones de células epiteliales cervicales de las cuales solo el $20 \%$ se reúne en la lámina portaobjeto, el traspaso de células es aleatorio y sujeto a error si las células anormales no se distribuyen de forma homogénea por toda la muestra. ${ }^{11}$

La falta de precisión en los diagnósticos basados en citologías realizadas entre 1972 y 1977 generó una serie de demandas en los Estados Unidos. Para 1978, The Wall Street Journal denunció a través de un informe a los laboratorios del este de EEUU donde se concluía que el excesivo volumen de muestras y los bajos costos sacrificaban la precisión del diagnóstico. Esto reduciría la calidad y la certeza del resultado. Más adelante y obligados por la ley de mejoramiento de laboratorios (1988), algunos de ellos establecieron que los errores se debían más al mismo procedimiento que a factor humano. Esto llevó al desarrollo de instrumentos computarizados y con mejor óptica, con lo que se creía que aumentaría la sensibilidad y disminuirían los falsos negativos. Sin embargo, se identificaron limitaciones en el muestreo y preparación. ${ }^{11}$

En respuesta a esta problemática en mayo de 1996 se aprueba el uso de Papanicolaou ThinPrep ${ }^{\mathrm{TM}}$ (Cytyc Corporation Boxborough, MA), por considerarse más efectivo para la detección de neoplasias intraepiteliales cervicales de bajo y alto grado. Al comparar las publicaciones de la literatura es posible separarlos en los de muestra dividida o compartida y los de uso deseado o directo al vial. La técnica de citología en base líquida resuelve cinco problemas: 1) falla en la captura de la totalidad de la muestra, 2) fijación deficiente, 3) distribución aleatoria de células anómalas, 4) existencia de elementos perturbadores y 5) calidad del frotis.

Este procedimiento debería disminuir los porcentajes de ASCUS por la mejor fijación y calidad en el portaobjetos. Sin embargo algunos estudios muestran relación favorable para la citología convencional. En referencia a las utilidades de la CBL para el tamizaje del cáncer cervical se encuentra una mayor sensibilidad para las lesiones intraepiteliales de alto grado en $\mathbf{7 7 . 8 \%}$ y carcinomas en $90.9 \%$ con el ThinPrep en comparación con el frotis convencional. ${ }^{12.13}$ 
En la actualidad existen estos medios preservantes dentro de los que encontramos el ThinPrep (hologic), SurePath (TriPath) comercializado por Becton Dickinson (BD) y LucBase brasilero. Los alcoholes empleados son etanol (SurePath) y metanol (T'hinPrep).

\section{Procesamiento de la CBL}

La muestra se recolecta con los citocepillos, se introduce en el vial con el líquido conservador (SurePath y ThinPrep) y se hace la respectiva marcación, lo que constituye la fase preanalítica. Los frascos se ponen en el vortex (agitador) con el fin de soltar las células adheridas a la cabeza del citocepillo que está en el medio líquido. Luego los frascos se colocan con tubos de centrifugación y jeringas en el BD PrepMate, se adicionan $4 \mathrm{ml}$ de reactivo de densidad a los tubos con lo cual se eliminan los desechos e inflamación de la muestra, se centrifuga y las células sedimentadas son transferidas a láminas cargadas SurePath (Rack) (capa deslizante que aumenta la adhesión celular), después se realiza la coloración que puede ser manual utilizando la técnica de Papanicolaou o el sistema PrepStain (automatizado). ${ }^{14}$

Desde el punto de vista morfológico SurePath y ThinPrep tienen mucho en común, ya que ambos ofrecen una muestra superior en comparación con la citología tradicional. El primero utiliza etanol como fijador y por lo tanto proporciona detalles celulares más familiares para el citólogo que el previsto por el otro que se fija con metanol. La metodología de los dos difiere en forma significativa. El ThinPrep obtiene una muestra con una membrana filtro de capa delgada a la que se aplica vacío. Esto atrapa las células de interés en la membrana y permite que se adhieran a un portaobjetos de vidrio para su análisis, pero si la muestra contiene sangre, moco, inflamación o necrosis, este material puede adherirse a la membrana y bloquear la adherencia de las células. En algunos casos puede conducir a una muestra insatisfactoria o no óptima. SurePath obtiene una muestra de capa fina utilizando un método de densidad de sedimentación. Esto enriquece la muestra celular mediante la exclusión de la sangre y la mayoría de las células inflamatorias, restos necróticos, moco y otros contaminantes, con lo cual el procedimiento ofrece siempre muestras adecuadas. ${ }^{15-18}$

Ambos métodos de recolección tienen validez para detectar lesiones cervicales significativas, además el SurePath tiene altas tasas de láminas satisfactorias y volumen residual suficiente para la captura de híbridos 2(CH2), inmunohistoquímica y pruebas de tipificación de VPH. En dos procesos se obtienen muestras finales con 50.000 a 75.000 células, en zonas circulares de $13 \mathrm{~mm}$ de diámetro. El componente endocervical es mínimo 10 células individuales o en grupos, y el escamoso mínimo de 5.000 células visualizadas por 8 a 10 células por campo de alto poder. ${ }^{19-21}$

\section{Procesamiento de la citología cérvicovaginal convencional}

Los siguientes son requisitos para la obtención de una muestra citológica con condiciones óptimas: el examen no debe realizarse durante la menstruación o antes de tres días de finalizado el último período, cuarenta y ocho horas previas al examen la paciente no debe haber realizado duchas vaginales, relaciones sexuales ni usado tampones, jabones, cremas o medicamentos vía vaginal.

Para la toma de la muestra se debe seguir una serie de procedimientos como son la rotulación de la lámina, la visualización del cuello uterino y en la zona de transformación se tomará la muestra mediante cepillos endocervicales y espátulas de madera o plásticas, luego se hace el extendido en la lámina para de inmediato aplicar aerosol fijador y enviarla al laboratorio de citología.

\section{Ventajas de la citología ginecológica en base líquida}

Las muestras son más representativas con mejor conservación disminuyen las insatisfactorias, aumentan las lesiones precursoras (en controversia), disminuye el número de ASCUS y de atipia glandular endocervical (AGC) (en controversia), disminuye el tiempo 
de lectura, se puede repetir el procedimiento, es fácil hacer estudios adicionales (inmunohistoquímica, FISH, tipificación de VPH y pueden ser guardadas hasta seis meses a $4^{\circ} \mathrm{C}$.

\section{Características morfológicas de la citología en base líquida}

Células endocervicales: conservan su disposición en "panal" y/o en "empalizada", forma más pequeña y redonda, grupos con mayor disociación celular, núcleos más pequeños y en ocasiones de morfología más reactiva. En comparación las endometriales mantienen su característica tridimensionalidad y núcleos de formas variables.

Atrofia: menos agrandamiento nuclear, sábanas de células parabasales bien conservadas y disminución de núcleos desnudos parabasales, aunque no del todo eliminados.

Células metaplásicas: conservan su disposición en "sábana" y/o empedrado y los procesos citoplasmáticos ("seudópodos"), citoplasma denso, homogéneo, con ligero aumento de la vacuolizacion, células aisladas más frecuentes, más pequeñas y redondas.

Cambios celulares reactivos asociados con inflamación, incluyendo la reparación: polaridad conservada con aumento uniforme del tamaño nuclear (dos veces el tamaño nuclear de la célula intermedia) y nucléolos más prominentes. En citología líquida los grupos reparativos son más redondeados que en los extendidos convencionales, hay halos perinucleares (“compás”), vacuolizacion citoplasmática y discromasia, similar a la visualizada en la citología convencional.

\section{Microorganismos}

Trichomona vaginalis: más pequeñas, a veces en forma de "barrilete", forma identificable del microorganismo con ocasional conservación del flagelo, mejor visualización de los núcleos y gránulos eosinófilos citoplasmáticos, manteniendo el patrón clásico de seudoeosinofilia celular con halos perinucleares

Cándida sp: células escamosas "engarzadas" sobre las seudohifas (efecto "brochettes"), seudohifas bien visualizadas con características similares a la citología convencional, esporas más pequeñas, redondeadas, con tendencia a agruparse y sin halos periféricos.

Cambio en la flora vaginal sugestivo de vaginosis bacteriana: en citología líquida como en convencional las células escamosas pueden estar cubiertas por una capa de bacterias ("células clave"), pero en la primera el fondo de la muestra está limpio.

Virus herpes: alteraciones citológicas superpuestas a las de la convencional, con mayor detalle, núcleos en "cristal esmerilado" con refuerzo de la membrana nuclear o inclusiones eosinófilas intranucleares rodeadas de halo claro, con frecuencia se advierten células epiteliales multinucleadas de gran tamaño y núcleos moldeados.

Adenocarcinoma endocervical in situ (AIS): células agrupadas en placas, tiras o rosetas y superposición nuclear, disposición celular en empalizada con los núcleos protruyendo en los bordes de los grupos ("plumaje" o "desflecado"), núcleos agrandados y elongados con estratificación y variación en la forma y tamaño, hipercromasia con cromatina granular y pequeños nucléolos, citoplasma escaso, bordes mal definidos y pérdida de la mucosecreción.

Componente escamoso del epitelio exocervical: la diferencia radica en que el tamaño es menor tanto del núcleo como del citoplasma. ${ }^{22-24}$

\section{Conclusiones y comentarios}

La citología en base líquida es una técnica alternativa que favorece el incremento en la detección de lesiones intraepiteliales escamosas y reducen el numero de extendidos insatisfactorios comparados con el método convencional. ${ }^{25} \mathrm{La}$ tasa de positividad de lesiones de bajo grado es más favorable lo cual se confirma en la 
biopsia. No se han encontrado diferencias significativas entre los métodos con el estándar de oro de verificación con colposcopia y biopsia si están indicados..$^{26-28}$

Los patólogos y citohistotecnólogos prefieren la citología en base líquida ya que facilita el tiempo de interpretación en el microscopio por la uniformidad de células epiteliales en una capa y la reducción de extendidos insatisfactorios. Como ventaja esta la posibilidad de realizar investigaciones en el remanente celular luego del examen citológico. Por último el espécimen en monocapa es el más apropiado para equipos de tamizaje automatizados. La técnica es más costosa en términos de implementación de equipos pero se compensa si la comparamos con la citología convencional en la que se observan altas tasas de anormalidades leves ASCUS, lo que genera elevado costo en el seguimiento, recursos y actividades de promoción y prevención en mujeres de alto riesgo. ${ }^{29-33}$

La mayoría de los estudios utilizan el método de tomar la citología cervicovaginal convencional y el remanente se transfiere al vial para la base líquida, llamado "split sample". Otros estudios toman la muestra por separado una para la convencional y otra para la base líquida que se realizan en mujeres con características epidemiológicas similares "directa al vial". Todos los estudios son verificados con el estándar de oro de colposcopia y biopsia. ${ }^{34-40}$

Comparada la base líquida con la convencional, la sensibilidad para el diagnóstico de ASCUS es de $90.4 \%$ y $88.2 \%$, en lesión intraepitelial escamosa de bajo grado (LSIL) $79.1 \%$ y $75.6 \%$, para lesión intraepitelial escamosa de alto grado (HSIL) $57.1 \%$ y $55.2 \%$. Con respecto a la especificad para la atipia de significado indeterminado (ASCUS) en base líquida es de $64.6 \%$ y $71.3 \%$, en convencional, para la lesión intraepitelial escamosa de bajo grado (LSIL) $78.8 \%$ y $81.2 \%$, para la lesión intraepitelial escamosa de alto grado (HSIL) $97.0 \%$ y $96.7 \%$. Estos hallazgos muestran que la citología en base líquida es más sensible pero no más específica que la convencional ${ }^{41-50}$ (Tabla 2).

Entre las nuevas alternativas para el tamizaje o cribado de lesiones precursoras de cáncer cervical encontramos las pruebas de detección de DNA del VPH y los esquemas mediante inspección directa con ácido acético VIA y con solución de Lugol VILI, las cuales han demostrado tener una mayor sensibilidad que la citología convencional.

\section{Pruebas de detección de VPH}

La presencia de VPHs-AR en el $99.7 \%$ en los carcinomas de cuello uterino se considera una causa necesaria para su desarrollo. Las pruebas de detección de VPH aisladas o en forma conjunta (co-testing) ofrecen mayor sensibilidad y especificidad para el diagnóstico de la enfermedad. En el año 2003 la agencia norteamericana de administración de alimentos y fármacos FDA autorizó la utilización de las pruebas de detección de DNA del VPH para el tamizaje del cáncer de cuello uterino en las mujeres mayores de 30 años en conjunto con la citología, dados los resultados de diferentes estudios clínicos que confirmaban su beneficio.

Un estudio del National Cáncer Institute en Portland, Oregón, realizado con 20.810 mujeres que fueron tamizadas con las dos pruebas, citología y VPH, y

Tabla 2. Comparación de sensibilidad y especificidad: citología base líquida vs convencional

\begin{tabular}{|c|c|c|c|c|}
\hline \multirow{2}{*}{$\begin{array}{c}\text { Categoria } \\
\text { diagnóstica }\end{array}$} & $\begin{array}{c}\text { Citología } \\
\text { líquida }\end{array}$ & $\begin{array}{c}\text { Citología } \\
\text { convencional }\end{array}$ & $\begin{array}{c}\text { Citología } \\
\text { liquida }\end{array}$ & $\begin{array}{c}\text { Especificidad } \\
\text { Convencional }\end{array}$ \\
\cline { 2 - 5 } ASCUS & $90 \%$ & $88.2 \%$ & $64 \%$ & $71.3 \%$ \\
LSIL & $79.1 \%$ & $75.6 \%$ & $78 \%$ & $81.2 \%$ \\
HSIL & $57.1 \%$ & $55.2 \%$ & $97 \%$ & $96.7 \%$ \\
\hline
\end{tabular}


que fueron seguidas por 45 meses reveló un valor predictivo negativo para NIC 3 o mayor de $99.84 \%$ para aquellas mujeres que presentaron las dos pruebas negativas $(99.47 \%$ y $99.76 \%)$ confirmando la necesidad de una primoinfección por VPH de alto riesgo en el desarrollo de la enfermedad. ${ }^{51}$

Hace poco se se publicaron dos estudios, uno en Suecia y otro en Holanda, que demuestran una vez más el beneficio de la tamización conjunta con citología y prueba de VPH. En el primero se detectó un $31 \%$ más de NIC 3 o mayor y en el Holandés un $70 \%$ en el primer tamizaje y durante el segundo tamizaje cuatro a cinco años después las cifras fueron $47 \%$ y $55 \%$ menos casos de NIC 3, argumentándose con estos hallazgos la posibilidad de espaciar los períodos de tamización en forma segura mejorando el costo-efectividad del tamizaje. ${ }^{52}$

En el 2006 el Dr. Cusick J. y col. publicaron ocho estudios clínicos estadounidenses y europeos que reúnen una casuística de 66.000 mujeres entre 30 y 66 años y que arrojan como resultado una mayor sensibilidad de las pruebas de VPH para la detección de NIC 2 o más de $96.1 \%$ comparada con la citología (53\%), aunque esta última mostró una mayor especificidad (90.7\% y $96 \%$ ) que las pruebas de $\mathrm{VPH}^{53}$ (Tabla 3 ). En Colombia se encuentran disponibles varias pruebas para la detección de VPH con registro del INVIMA para su comercialización y utilización, las cuales han sido incluidas hace poco dentro del programa de salud obligatorio POS 2012 para tamizaje.

Estan aprobadas la prueba de captura Híbridos II del laboratorio Quiagen que detecta los 13 tipos virales de alto riesgo mediante técnicas de hibridación in situ (16,

\begin{tabular}{|c|c|c|}
\hline $\mathrm{N}: 66.000$ & Citología & Test de VPH \\
\hline Sensibilidad & $53 \%$ & $96 \%$ \\
\hline Especificidad & $96.3 \%$ & $90.7 \%$ \\
\hline VPP & $20.2 \%$ & $15.5 \%$ \\
\hline
\end{tabular}

Adaptado de Cuzick et al Int JCancer2006; I19:1095-101.
$18,31,33,35,39,45,51,52,56,58,59$, y 68$)$ y las de PCR de laboratorios Roche Amplicor y de Linear Arrays que identifican la presencia de 13 y 34 tipos de VPH de alto riesgo por medio de técnicas de amplificación de la fracción L1 del genoma utilizando la reacción en cadena de polimerasa y desde abril de 2011 fueron aprobadas por la FDA las pruebas automatizadas de PCR Cobas 4800 y Real Time de laboratorios Roche y Abbott, las cuales tipifican un virus más de alto riesgo, el VPH 66, y realizan en forma simultánea genotipificación para los VPH 16 y 18 .

También se encuentra disponible y aprobada Aptima una prueba de laboratorios Gen Probes que detecta los oncogenes RNA E6 y E7 de los 14 tipos de VPH de alto riesgo, los cuales están relacionados en forma directa con la inactivación del gen del retinoblastoma (Rb) y el oncogén P57, oncoproteinas encargadas de la apoptosis celular y cuya inactivación es la génesis de la transformación maligna celular.

\section{Tamización mediante inspección visual con ácido acético y lugol (vía y vili)}

La tamización mediante la utilización de ácido acético al 5\% para impregnar el cervix durante un minuto y su posterior visualización directa mediante una lámpara de luz fria, denominada inspección visual con ácido acético (VIA) ha demostrado tener una mayor sensibilidad $67-74 \%$ vs $44-78 \%$ de la citología. La inspección visual utilizando la misma técnica pero con solución de Lugol VILI presenta una sensibilidad del $78 \%$ al $98 \%{ }^{54}$ (Tabla 4 ).

En áreas apartadas del país donde no es factible garantizar el desarrollo de un programa de tamizaje fundamentado en la citología, las técnicas de inspección visual VIA-VILI ofrecen muchas ventajas dado que permiten una mayor cobertura del programa, un mejor seguimiento de la atención y un diagnóstico y tratamiento oportunos. Esto obedece a que para su implementación requiere menos personal especializado, una infraestructura más sencilla, equipos poco costosos y una menor capacitación para su implementación y 
Tabla 4. Sensibilidad y especificidad de la citología convencional vs pruebas de VPH, inspección visual con ácido acético VIA y solición del lugol VILLI

\begin{tabular}{|l|c|c|}
\hline Prueba de cribado & Sensibilidad & Especificidad \\
\hline Citología convencional & $44-78 \%$ & $96-98 \%$ \\
Pruebas de VPH & $66-100 \%$ & $61-96 \%$ \\
VIA & $67-74 \%$ & $49-86 \%$ \\
VILI & $78-98 \%$ & $73-93 \%$ \\
\hline
\end{tabular}

desarrollo. Lo más importante es que con esta técnica se puede informar el resultado de manera inmediata a las pacientes, lo que permite realizar un tratamiento mediante crioterapia, mejorando significativamente la oportunidad dentro de un esquema de "ver y tratar". Los esquemas de inspección visual han demostrado una disminución del 25 al 36\% el riesgo de cáncer de cuello uterino con una única visita según los estudios realizados en India, Kenia, Perú, Sudáfrica y Tailandia, y si se realizan dos visitas a lo largo de la vida con un intervalo de diez años este puede disminuir un $40 \%$ más. ${ }^{55}$

\section{Referencias}

1. David Oddó B. MD. George Nicholas Papanicolaou. Vida y Obra de uno de los médicos más conocidos del siglo XX (I y II partes). http://www.sld.cu/galerias/ pdf/sitios/histologia/georgenicholaspapanicolaou.pdf Consultado24/02/2012 7:57 am.

2. Recomendaciones para la tamización de neoplasias del cuello uterino en mujeres sin antecedentes de patología cervical (preinvasora o invasora) en Colombia. ISBN_978-958-98496-4-4 Guías de práctica clínica (No. 3) Ministerio de la protección social, Instituto Nacional de Cancerología. Disponible http://www. cancer.gov.co/documentos/RecomendacionesyGuias/GuiaN3.pdf Consultado Febrero 18-2012 6:54p.m.

3. GLOBOCAN 2008, International Agency for Research on Cancer

4. Cuzick J, et al. Overview of the Europan and North American studies on HPV testing in primary cervical screening. Int J Cancer 2006; 1 19(5):1905-110.

5. Maribel Almonte, PhD, Raúl Murillo, MD, Gloria Inés Sánchez, PhD. Nuevos paradigmas y desafíos en la prevención y control del cáncer de cuello uterino en América Latina. Salud Pública de México / vol. 52, no. 6, noviembre-diciembre de 2010.

6. Ricardo Cendales, Marion Piñeros, Carolina Wiesner, Raúl Murillo, Sandra Tovar. Cobertura de la citología cérvico-uterina y factores relacionados en cuatro departamentos de Colombia. Rev Colomb Cancerol 2008; 12(3):1 19-125.

7. Libro Blanco de la Anatomía Patológica en España. Sociedad Española de Anatomía Patológica. Citopatología pág. 57

8. Paolo Ricci A., Emesto Perucca P.. Josip Koljanin V., Eduardo Baeriswyl T Citología de base líquida: Revisión de la historia y los estudios al respecto. Rev Chil Obstet Ginecol 2004; 69 (3): 256-262.
9. Hutchinson ML, Zahniser DJ, Sherman ME, Herrero R, Alfaro M, Bratti MC, Hildesheim A, Lorincz AT, Greenberg MD, Morales J, Schiffman M. Utility of liquid-based cytology for cervical carcinomas screening: results of a populationbased study conducted in a region of Costa Rica with a high incidence of cervical carcinoma. Cancer 1999; 87(2): 48-55.

10. New Options for Cervical Cancer Screening and Treatment in Low-Resource Settings. Cervical Cancer Action Coalition / New options for cervical cancer screening and treatment. Disponible http://www.rho.org/files/CCA_cervical_ cancer_screening_treatment.pdf

11. Taoka Hideki MD. Comparasion of convencional and liquid-based cytology, and human papillomavirus testing using SurePath preparation in Japan. Human Cell 2010; 23:126-133.

12. Arbyn Marc, MD, Bergeron Christine, MD, PhD. Liquid compared with conventional cervical cytology. Obstet Gynecol 2008; 111:167-77

13. Sherman ME, Lorinez AT, DR. Baseline cytology,human papillomavirus testing and risk for cervical neoplasia:al 0-year cohort analysis. Jnatl Cancer Inst 2003;95:46-52.

14. Naucler P, TornbergS, etal. Human papillomavirus and Papanicolaou tests to screen for cervical cancer. N Engl J Med 2007:357:1589-97.

15. Bulkmans NW, Berkhof.l, RozendaalL, etal. Human papilloma virus DNA testing for the detection of cervical intraepitelial neoplasia grade 3 and cancer:5-year follow- upofa randomised controlled implementation trial.Lancet 2007;37:1764-72.

16. CuzickJ, ClavelC, PetryKU, etal. Overview of the European and North American studies on HPV testing in primary cervical cancer screening. Int J Cancer 2006; 119: $1095-101$

17. Controversias en Ginecología y Obstetricia 2008; 20 (114); 3861-71.

18. Goldie $\mathrm{Sj}$, Gaffikin L et al. Cost-effectiveness of cervical-cáncer screening in five developing countries. N Eng J Med 2005;353(20):2158-68.

19. Abulafia O, Pezzullo JC, Sherer DM: Performance of ThinPrcpliquid-based cervical cytology in comparison with conventionally prepared Papanicolaou smears: A quantitative survey. Gynecol Oncol 2003; 90:137-144.

20. Baker J: Conventional and liquid-based cervicovaginal cytology: A comparison study with clinical and histologic follow-up. Diagn Cytopathol 2002; 27:185188. Bavikatty NR, Michael CW. Cytologic features of small-cell carcinoma on ThinPrep(B. Diagn Cytopathol 2003; 29:8-12.

21. Bernstein SJ, Sanchez-Ramos L, Ndubisi B.: Liquid-based cervical Cytologic smear study and conventional Papanicolaou smears: A metaanalysis of prospective studies comparing Cytologic diagnosis and sample adequacy. Am J Obstet Gynecol 2001; 185:308-317.

22. Austin RM, Ramzy I. Increased detection of epithelial cell abnormalities by liquid-based gynecologic cytology preparations. A review of accumulated data. Acta Cytol 1998; 42:178-184.

23. Merea E, Le Gales C, Cochand-Priollet B, Cartier I, de Cremoux P, VacherLevenu MC, Vielh P, Coste J. Cost of screening for cancerous and precancerous lesions of the cervix. Diagn Cytopathol 2002: 27:251-257.

24. Selvaggi SM: Cytologic features of high-grade squamous intraepithelial lesions involving endocervical glands on ThinPrep cytology. DiagnCytopathol 2002; 26:181-185

25. Salud femenina. Citología en Base Liquida Disponible: www.mujersaludable. blogspot.com. Fecha de acceso 09-10-2001.

26. Gilbert Bigras, MD, FRCPC, PhD, 1 Malgorzata Anna Rieder, CT, 1 Jean-marc Lambercy, MD, 2 Bernard Kunz, MD, 2 Jean-Paul Chatelain, MD, 2 Olivier Reymond, MD, 2 and Daniel Cornaz, MD2. Keeping Collecting Device in Liquid Medium Is Mandatory to Ensure Optimized Liquid-Based Cervical Cytologic Sampling. Rev Journal of Lower Genital Tract Disease, Volumen 7, Number 3, 2003, 168-174.

27. Maurice Fremont-Smith, M.D.I James Marino, B.S., CMIACl Bryan Griffin, M.D.2 Lynn Spencer, David Bolick, M.D., MIAC. Comparison of the SurePath'⿳ Liquid-Based Papanicolaou Smear with the Conventional Papanicolaou Smear in a Multisite Direct-to-Vial Study. Rev Cancer Cytopathology published online 31 August 2004 in Wiley InterScience. 
28. Brenda J. Sweeney, C.T. 1 Zafarul Haq, M.T., C.T.1 James F. Happel, D.L.M.1 Barbará Weinstein, M.D.2 Douglas Schneider, M.D.1.Comparison of the Effectiveness of Two Liquid-Based Papanicolaou Systems in the Handling of Adverse Limiting Factors, such as Excessive Blood. Rev Cancer Cytopathology published online 21 November 2005 in Wiley InterScience.

29. Colgan TJ, McLachlin CM, Cotterchio M, Howlett R, Seidenfeld AM, Mai VM. Cancer Cytopathology. 2004; 102(6):362-367.

30. Keith V. Nance, M.D. Evolution of Pap Testing at a Community Hospital- A Ten Year Experence. Diagnostic Cytopathology 2007, Vol. 35, Issue 3,148-153.

31. Hazem T. Jafer, Mathilde E. Boon and Elizabeth Ouwerkerk-Noordam Leiden Cytology and Pathology Laboratory, Leiden, The Netherlands. Catching properties of brushes used in ThinPred-liquid-based cytology. Disponible http://www. klinicyte.nl/26/SurePath -LBC-in-Nederland.html. Consultado Marzo 11-2012.

32. Ronco Guglielmo, Cruzick Jack. Accuracy of liquid based versus conventional cytology: overall results of new technologies for cancer cervical screening: randomized controlled trial. Bmj.com 4 august 2008.

33. Fang-Hui Zhao, MD, PhD; Shang-Ying Hu, MD. Comparison of ThinPred and SurePath Liquid-Based Cytology and Subsequent Human Papillomavirus DNA Testing in China. Cancer Cytopathology Month 00, 2011.

34. Wright P.K. Comparison of SurePath and ThinPred liquid-based cervical cytology using positive predictive value, atypical predictive value and total predictive value as performance indicators. Cytopathology 2010; 21:374-378.

35. Bergeron Christine MD., PhD. Accuracy of Thin-Layer cytology in patients undergoing cervical cone biopsy. Acta Citológica 2001; 45:519-524.

36. Kenyon Shelly, MD. Comparasion of BD SurePath and ThinPred pap systems in the processing of mucus rich specimens. Cancer Cytopathology 2010; 25:244249.

37. Allen C. Rinas, M.S., C.T. (ASCP), C.M.I.A.C., Benjamín W. Mittman, Jr., B.S., et al. Split - Sample Analysis of Discarded Cells from Liquid - Based Pap smear Sampling Devices. Acta Cytologica 2006-50:55-62.

38. Cheung AN, Szeto EF, Leung BS, Khoo US, Ng AW. Liquid based cytology and convencional cervical smears Cancer 2003; 99(6): 331-5.

39. Vassilakos P, Schwartz D, de Marval F, Yousfi L, Broquet G, Mathez-Loic F, Campana A, Major A. Biopsy-base comparison of liquid-based, thin-layer preparations to conventional Pap smears. J Reprod Med 2000; 45(1): 116.

40. Bogdanich W. Lex Laboratories: The Pap test misses much cervical cancer through labs 'errors. The Wall Street Journal, November 11, 1987.

41. Guidos BJ, Selvaggi SM. Use of the Thin Prep Pap Test in clinical practice. Diagn Cytopathol 1999; 20(2): 70-3.
42. McGoogan E. Liquid-based cytology: the new screening test for cervical cancer control. Journal of Family Planning and Reproductive Health Care 2004; 30 : 123-125.

43. Lewis, MJ. Análisis de la situación del cáncer cervico uterino en América Latina y el Caribe. Washington, DC: Organización Panamericana de la Salud / Organización Mundial de la Salud (OPS/OMS), 2004.

44. World Health Organization. Cytology screening. [Revista en línea] fecha de acceso 24/02/09, Disponible en www.who.int/entity/cancer/detection/cytologyscreen/en/index.html.

45. César La cruz Pelea. Nomenclatura de las lesiones cervicales (de Papanicolaou a Bethesda 2001). Revista Española de Patología. 2003; 36.

46. American College of Obstetricians and Gynecologists. ACOG committee opinion. Recommendations on frequency of Pap test screening. Number 152-March 1995.Committee on Gynecologic Practice. Int J Gynecol Obstet 1995; 49:210-1.

47. Javier Sáenz de Santamaría, Julio Rodríguez Costa, Domingo de Agustín Vásquez. Cuademos de Citopatología

48. Klinkhamer PJ, Meerding WJ, Rosier PF, Hanselaar AG. Liquid based cervical cytology. Cancer.2003; 99:263-271.

49. Nanda K, McCrory DC, Myers ER, et al. Accuracy of the Papanicolaou test in screening for an follow up of cervical cytologic abnormalities systematic review. Ann Intern Med. 2000; 132:810-819.

50. Maksem J. A manual method of liquid based cytology: Implementation, testing, cot and outcomes. American Society for Clinical Pathology Teleconference Series, 2004

51. Lee JM, Kelly D, Gravitt PE, Fansier Z, Maksem JA, Clarck DP. Validation of a low cost, liquid based screening method for cervical intraepithelial neoplasia. Am J Obstet Gynecol 2006; 195:965-70.

52. CelikC, Gezginc K, Toy H, Findik S, Yilmaz O. A comparison of liquid based cytology with conventional cytology. Int J Gynecol Obstet 2008; 100:263-6.

53. Gustafsin KS, Fuerth EE, Heitjan DF, Fansier ZB, Clarc DC. DNA methylation profiling of cervical squamous intraepithelial lesions using liquid based cytology specimens. Cancer Cytopathol 2004; 102:259-68.

54. Rosenthal DL, Geddes S, Trimble CL, Carson KA, Alli PM. The PapSpin: A: A reasonable alternative to other, more expensive liquid-based Papanicolaou test. Cancer 2006; 108:137-43.

55. Kavatkar AN, Nagwanshi CA, Dabak SM. Study of a manual method of liquidbased cervical cytology.2008; 51:190-4. 